\title{
Special Event Sebagai Sarana Meningkatkan Citra Panasonic Beauty
}

\author{
Adinda Mutiara Pratiwi ${ }^{1}$, Mahdiah ${ }^{2}$ \\ 1,2, Institut Komunikasi dan Bisnis LSPR
}

\begin{abstract}
ABSTRAK
PT Panasonic Gobel Indonesia adalah sebuah perusahaan manufaktur kelas dunia di bidang elektronik, khususnya untuk kebutuhan konsumen awam, bisnis dan industri. Beberapa tahun terakhir, Panasonic meluncurkan sebuah produk baru yaitu Panasonic Beauty yang belum luas distribusinya sehingga citranya pun masih kurang di kalangan masyarakat. Tujuan dari perencanaan konsep ini adalah untuk meningkatkan citra Panasonic Beauty, disamping produk-produk elektronik Panasonic lainnya yang juga telah lama eksis di Indonesia. Perencanaan ini berupa strategi Public Relations roadshow campusto-campus bernama "Girls Beauty Room by Panasonic Beauty" yang telah kami rancang. Perencanaan strategi ini dibuat menggunakan teori 9 Steps Strategy of Public Relations oleh Ronald D. Smith. Strategi yang digunakan adalah membuat special event "Girls Beauty Room by Panasonic Beauty" yang terdiri dari pre-event, special event, dan post-event. Pre-event berupa penyelenggaraan press conference untuk media terpilih sebagai wadah untuk mempromosikan special event. Special event "Girls Beauty Room by Panasonic Beauty" mencakup 3 acara yaitu talkshow, free hairstyling di mobile salon, dan perlombaan foto di Instagram Panasonic Beauty. Rangkaian acara diakhiri dengan post-event berupa evaluasi dan media monitoring. Untuk hasil akhir (evaluasi), perencanaan ini menggunakan 6 langkah evaluasi yaitu menghitung berapa media yang datang, menghitung berapa banyak partisipan special event, menganalisis antusiasme dari partisipan special event, menghitung berapa banyak publik yang memberikan publikasi, melakukan media monitoring, menghitung berapa persen citra Panasonic Beauty yang meningkat setelah kegiatan acara dilakukan.
\end{abstract}

Kata kunci: Panasonic; komunikasi; strategi public relations; special event; citra

\begin{abstract}
PT Panasonic Gobel Indonesia is a world-class manufacturing company in the field of electronics, especially for lay consumers, business and industry. In recent years, Panasonic has launched a new product, Panasonic Beauty, which has not been widely distributed so the image is still lacking among the public. The purpose of this concept planning is to improve the image of Panasonic Beauty, in addition to another Panasonic electronic products that have been long existed in Indonesia. This plan is including Public Relations strategy such as campus-to-campus roadshow called "Girls Beauty Room by Panasonic Beauty" that we have planned. The Public Relations strategy is made using the 9 Steps Strategy of Public Relations theory by Ronald D. Smith. The planner used this method to make a special event "Girls Beauty Room by Panasonic Beauty" which consists of pre-events, special events, and postevents. Pre-event is including press conferences for selected media as a place to promote special events. The special event "Girls Beauty Room by Panasonic Beauty" includes 3 events, namely talk shows, free hairstyling at mobile salons, and photo competitions on Panasonic Beauty Instagram. The strategy ended with a post-event such as evaluation and media monitoring. For the final results (evaluation), this planning uses 6 evaluation steps, which are calculating how many media came, counting how many special event participants, analyzing the enthusiasm of special event participants, calculating how many
\end{abstract}


publics gave publications, conducting media monitoring, calculating what percentage of the image Panasonic Beauty which increased after the event was held.

Keywords: Panasonic; communications; public relations strategy; special event; image

\section{PENDAHULUAN}

Dewasa ini, citra merupakan salah satu komponen yang penting dalam berjalannya suatu perusahaan. Namun dalam membentuk citra perusahaan, diperlukan berbagai strategi yang dilakukan oleh Public Relations. Berkembangnya dunia Public Relations menjadikan semakin banyak pula cara untuk meningkatkan citra suatu perusahaan. Beberapa strategi yang dapat dilakukan oleh perusahaan diantaranya yaitu kampanye, corporate social responsibility, maupun special event. Termasuk di dalam industri kecantikan, semakin banyaknya produk kecantikan maka sebuah perusahaan harus semakin gencar dalam membentuk serta meningkatkan citra produk kecantikan tersebut.

Saat ini, industri kecantikan sangat berkembang di dunia termasuk Indonesia. Para wanita dari berbagai kalangan remaja atau orang dewasa kini semakin memedulikan penampilannya, mulai dari gaya pakaian, riasan wajah, maupun tatanan rambut. Hal ini merupakan sebuah opportunity bagi perusahaan manufaktur di bidang elektronik, guna menyajikan ragam produk berkualitas untuk memaksimalkan penampilan.

PT Panasonic Gobel Indonesia adalah sebuah perusahaan manufaktur kelas dunia di bidang elektronik, khususnya untuk kebutuhan konsumen awam, bisnis dan industri. Produk elektronik yang telah diproduksi oleh Panasonic antara lain adalah telepon, kulkas, air conditioner, baterai, televisi, DVD, kamera, peralatan memasak, dan peralatan kecantikan. Hingga saat ini, beberapa produk Panasonic berhasil meraih peringkat 5 besar Top Brand oleh Frontier Consulting Group tahun 2016.Sebagai perusahaan yang kredibel, PT Panasonic Gobel Indonesia menyadari akan pentingnya citra terhadap keberlangsungan perusahaan. Oleh sebab itu, PT Panasonic Gobel Indonesia telah menyelenggarakan beberapa strategi Public Relations dalam rangka meningkatkan citra perusahaan, seperti mengadakan special event, corporate social responsibility, dan kampanye.

Adapun beberapa contoh program yang telah dilaksanakan oleh PT Panasonic Gobel Indonesia, seperti special event "Panasonic Gobel Awards"yang telah terlaksana sebanyak 19 kali secara berkala. "Panasonic Gobel Awards" merupakan special event pemberian penghargaan kepada insan pertelevisian Indonesia. Pada pelaksanaannya yang ke 19, "Panasonic Gobel Awards" dihadiri sebanyak 66 media dan berhasil mendapat publikasi melalui berbagai media cetak, televisi, dan online.

Selain special event, PT Panasonic Gobel Indonesia turut melakukan program Corporate Social Responsibility, seperti "Kid Witness News", yaitu sebagai bentuk kepedulian Panasonic terhadap pengembangan potensi anak-anak di Indonesia. PT Panasonic Gobel Indonesia juga 
telah melakukan beberapa kampanye, diantaranya adalah kampanye baterai ramah lingkungan. Awal tahun 2015, Panasonic mengkampanyekan produk baterai tanpa zat timbal dan merkuri. Kampanye tersebut bertujuan untuk mengurangi pencemaran lingkungan melalui limbah pabrik baterai, dengan tema "Jodohnya Remote" sesuai dengan kegunaan baterai Panasonic. Melalui “Jodohnya Remote", Panasonic menunjukkan kepada publik akan kepeduliannya terhadap lingkungan dan kesejahteraan masyarakat dengan cara mengurangi limbah.

Sebagai bentuk pengembangan terhadap industri kecantikan, tepat di tahun 2013, Panasonic kembali mengembangkan industrinya dengan memproduksi alat-alat kecantikan untuk wanita, yang dinamakan Panasonic Beauty. Sebagian besar produk dari Panasonic Beauty merupakan hair dryer, hair styler, face ionic, eyelash curler, dan lain-lain. Tak hanya itu, Panasonic Beauty pun turut mengembangkan teknologi Nanoe yang dapat memberi perawatan untuk rambut dan kulit wajah.

Namun, permasalahan yang sedang dihadapi Panasonic Beauty adalah citra Panasonic Beauty belum sebaik citra produk Panasonic lainnya. Berdasarkan data yang didapat dari Top Brand Award oleh Frontier Consulting Group pada tahun 2017, dalam kategori alat kecantikan, Panasonic Beauty belum berhasil mendapati predikat TOP dan masih memiliki jumlah persenan hanya sebesar $6,1 \%$. Hal ini sangat berbanding terbalik dengan kompetitor utama Panasonic yaitu brand Phillips yang menduduki urutan pertama dengan jumlah persenan sebesar 42,6\%. Data ini lah yang membuktikan bahwa distribusi dan citra Panasonic Beauty masih kurang apabila dibandingkan dengan produk elektronik Panasonic yang sudah lebih dulu terkenal di masyarakat. Apabila hal ini tidak secepatnya dibenahi, maka produk Panasonic Beauty akan selalu mendapati peringkat bawah dan tidak mendapat gelar TOP Brand. PT Panasonic Gobel Indonesia pun akan gagal mengembangkan industri nya dalam bidang kecantikan.

Alasan tersebut memotivasi kami untuk membuat program Public Relations untuk meningkatkan citra Panasonic Beauty. Dalam meningkatkan citra, maka dibutuhkan suatu perencanaan strategi, dimana strategi tersebut harus memiliki news value. Dengan adanya news value, maka diharapkan strategi yang telah dirancang dapat menarik perhatian media dan publik, sehingga tujuan untuk meningkatkan citra Panasonic Beauty dapat tercapai. Oleh karena itu, kami akan membuat perencanaan strategi Public Relations untuk Panasonic Beauty, yaitu mengadakan rangkaian special event yang mengusung konsep campus-to-campus bernama "Girls Beauty Room by Panasonic Beauty". Mengingat bahwa saat ini maraknya beauty influencers yang digemari oleh para wanita masa kini, kami pun merancang acara dengan menggunakan Beauty Influencers yang sangat aktif di berbagai platform media sosial mulai dari Instagram hingga Youtube. Kami merangkai program ini menjadi 3 bagian yaitu Pre-Event, Special Event, dan Post-Event. Program ini memiliki tujuan untuk meningkatkan citra Panasonic Beauty di mata publik, disamping produk-produk elektronik Panasonic lainnya yang juga telah lama berkomitmen dalam bidang elektronik di Indonesia.

Dalam merancang strategi Public Relations "Girls Beauty Room by Panasonic Beauty" perencana menggunakan teori 9 Steps Strategy for Public Relations menurut Ronald D. Smith 
dalam bukunya yang berjudul Strategic Planning for Public Relations pada tahun 2009. Teori ini terbagi atas empat langkah, yaitu sebagai berikut: (1) Formative Research. Pada fase pertama dalam merencanakan program Public Relations, Formative Reseach berfokus kepada mengumpulkan informasi dan menganalisis situasi. Pada tahap ini, perencana program mengumpulkan informasi yang berhubungan dengan suatu organisasi atau perusahaan, sekaligus melakukan penelitian yang bertujuan untuk menambah informasi sebagai pendorong terciptanya suatu keputusan.Terdapat tiga langkah dalam fase Formative Research. Yang pertama adalah menganalisis situasi, yang kedua adalah analisis organisasi, dan langkah terakhir adalah analisis publik. (2). Strategy. Untuk mencapai suatu kesuksesan dalam program Public Relations, tentunyadibutuhkan perencanaan strategi. Terdapat 3 tahap dalam fase strategi, yaitu menentukan tujuan dan sasaran, memformulasikan aksi dan strategi respon, dan penggunaan komunikasi yang efektif. (3). Tactics. Pada fase ini terdapat dua langkah, yaitu menentukan taktik dalam komunikasi dan mengimplementasikan strategi yang telah direncanakan. Dalam menentukan taktik untuk komunikasi, perencana harus mempertimbangkanstrategi komunikasi secara interpersonal, publikasi yang dikeluarkan dari organisasi, adanya publisitas yang kredibel dari media lain, dan iklan atau media promosi lainnya untuk khalayak luas. Pada tahap selanjutnya, perencana dapat menyusun anggaran dan timeline untuk pelaksanaan program yang akan dijalankan. (4). Evaluative Research. Tahap yang terakhir adalah Evaluative Research. Setelah terselenggaranya program, maka dibutuhkan adanya evaluasi untuk mengukur keberhasilan strategi yang telah disusun. Perencana dapat mengetahui seberapa besar keberhasilan program yang telah dijalankan dan mengukur seberapa efektif program tersebut dalam mencapai tujuan yang telah ditetapkan. Dengan adanya evaluasi, maka perencana dapat mengetahui kelebihan dan kekurangan terhadap program yang telah dijalankan, agar menjadi referensi maupun perbaikan untuk program selanjutnya.

Menurut kalangan pakar komunikasi antara lain yang dihimpun dari berbagai sumber (Ruslan, 2001), sebagai berikut:

"A special event is an event of which usually produced to gain favourable attention in media for your client, your company or your product. It may also be designed to convey a specificmessages about your company; for example, the fact of your company provides equal employment opportunity, is a good place to work, is a sociality responsible corporate citizen, is good neighbor, is interested progress for woman, manufactures fine products, or is as substantial tax prayer in community. A special event might also be product launch or a product publicity event."

Menurut Ruslan (2001) dalam bukunya yang berjudul Manajemen Public Relations dan Media Komunikasi, special events dari Public Relations memiliki beberapa peranan, yaitu meningkatkan pengetahuan (knowledge), pengenalan (awareness), upaya pemenuhan selera (pleasure), serta menarik simpati atau empati.

Frank Jefkins dalam bukunya yangberjudul Public Relations (2001), mengatakan ada beberapa jenis citra, yakni: (1) Citra bayangan adalah citra yang dianut oleh orang dalam mengenai pandangan luar terhadap organisasinya. (2) Citra yang berlaku (current image) ini adalah suatu 
citra atau pandangan yang dianut oleh pihak-pihak luar mengenai suatu organisasi. (3) Citra harapan (wish images) adalah suatu citrayang diinginkan oleh pihak manajemen. Citra yang diharapkan biasanya lebih baik atau lebih menyenangkan daripada citra yang ada; walaupun dalam keadaan tertentu, citra yang terlalu baik juga bisa merepotkan. (4) Citra perusahaan adalah citra dari suatu organisasi secara keseluruhan, jadi bukan sekedar citra atas produk dan pelayanannya. Citra perusahaan ini terbentuk dari banyak hal, seperti sejarah atau riwayat hidup perusahaan yang gemilang, keberhasilan dan stabilitas di bidang keuangan, kualitas produk, keberhasilan ekspor, hubungan industri yang baik, reputasi sebagai pencipta lapangan kerja, kesediaan turut memikul tanggung jawabsosial, dan komitmen mengadakan riset. (5) Banyaknya jumlah pegawai, cabang atau perwakilan dari sebuah perusahaan atau organisasi dapat memunculkan citra yang belum tentu sama dengan citra organisasi atau perusahaan tersebut secara keseluruhan. (6) Citra yang Baik dan yang Buruk. Citra Public Relations yang ideal adalah kesan yang benar, yakni sepenuhnya berdasarkan pengalaman, pengetahuan, serta pemahaman atas kenyataan yang sesungguhnya. Suatu citra yang lebih baik sebenarnya bisa dimunculkankapan saja, termasuk di tengah terjadinya musibah atau sesuatu yang buruk.

Menurut George Black (Chicago: Putnam Publishing, 1952) pada buku Kampanye Public Relations (dalam Ruslan, 2008, p.50), publisitas Public Relations lebih menekankan fungsi perusahaan secara utuh, mengatakan sebagai berikut:

"Publisitas mencakupi, mendapatkan ruang editorial yang berbeda dari ruang kolom yang dibayar di semua media yang dibaca, dilihat, dan didengar oleh konsumen perusahaan atau calon-calon konsumen dengan maksud khusus untuk membantu mencapai tujuan-tujuan penjualan (p.50).”

Menurut Cutlip, Center, dan Broom, dalam bukunya yang berjudul Effective Public Relations (2006, p.10-11), pengertian publikasi adalah informasi yang diberikan oleh sumber dari luar, yang digunakan oleh media karena informasi tersebut memiliki news value. Adanya news value dalam program Public Relations dapat menarik perhatian media, sehingga dapat meningkatkan publisitas.

Media merupakan sarana terbaik dalam mempublikasikan program Public Relations (Laermer \& Prichinello, 2009, p.32), karena media atau pers memberi suatu validitas terhadap apa yang dikatakan oleh narasumber. Selain itu, liputan berita secara implisit juga lebih berpengaruh untuk publik.

\section{METODE PENELITIAN}

Untuk mendapatkan hasil yang diharapkan, maka digunakan 9 Steps Strategy for Public Relations (Smith, 2013) yang terbagi atas empat langkah, yaitu formative research, strategy, tactics, dan evaluative research. Diikuti dengan analisis SWOT. Dalam merencanakan suatu program Public Relations khususnya special event, sangat diperlukan menganalisis publik yang dijadikan target dalam mensukseskan acara tersebut, yaitu sebagai berikut: 
A. Demografi

Jenis Kelamin: Wanita

Usia :

- Primer: 18 - 23

- Sekunder: 24 - 45

Segmentasi : Menengah keatas

B. Geografi

Lokasi: DKI Jakarta

C. Psikologi

Mahasiswi yang tertarik dengan kecantikan dan memiliki kebutuhan alat kecantikan dan perawatan diri.

\section{HASIL DAN PEMBAHASAN}

Perencana menggunakan 9 Steps Strategy for Public Relations (Smith, 2013) yang terbagi atas empat langkah, yaitu formative research, strategy, tactics, dan evaluative research. Pada langkah pertama (formative research), perencana akan menganalisis situasi, perusahaan atau organisasi, dan publik. Langkah pertama digunakan oleh perencana untuk mengetahui situasi yang sedang dihadapi, sehingga dapat dijadikan pedoman dan pertimbangan dalam mengambil keputusan untuk memulai perencanaan program Public Relations. PT. Panasonic Gobel Indonesia merupakan perusahaan dalam bidang elektronik yang sudah dikenal produknya dan banyak dipakai oleh masyarakat baik di Indonesia maupun di negara lainnya.Panasonic tidak hanya meningkatkan kualitas dan pelayanan yang baik kepada masyarakat. Namun, Panasonic juga memulai beragam elektronik dengan jenis baru, seperti alat-alat kecantikan, yaitu Panasonic Beauty. Oleh karena itu, PT. Panasonic Gobel Indonesia merencanakan strategi Public Relations dalam bentuk meningkatkan citra Panasonic Beauty. Strategi ini diharapkan dapat meningkatkan citra atau kesadaran publik terhadap PT. Panasonic Gobel Indonesia, dan memilih Panasonic sebagai produk alat eletronik kecantikan.

Analisis SWOT merupakan analisis yang berguna untuk berbagai penelitian dalam bidang komunikasi, termasuk dalam merencanakan program Public Relations. Analisis SWOT (strenghts, weakness, opportunities, threats) merupakan analisis perusahaan secara internal dan eksternal, dimana strenghts dan weakness adalah analisis internal, sedangkan opportunity dan threats adalah analisis eksternal. (1). Strength. Panasonic adalah perusahaan multinasional yang produknya sudah banyak dikenal di berbagai negara. Di Indonesia, Panasonic sudah menjadi produk elektronik yang memiliki kualitas baik, banyak dipakai oleh masyarakat dan berhasil meraih Top Brand Award. Panasonic berpengalaman dalam menyelenggarakan beberapa Public Relations program, seperti Corporate Social Responsibility dan Special Event. (2) Weakness. Panasonic memiliki range harga yang tinggi sehingga hanya bisa menjangkau publik yang memiliki keadaan ekonomi menengah keatas. Panasonic Beauty belum memiliki jangkauan distribusi yang luas. (3) Opportunity. Tekonologi yang semakin berkembang dan peralatan elektronik selalu dibutuhkan oleh masyarakat. Panasonic memiliki banyak peluang untuk meningkatkan citra melalui sponsorship untuk berbagai event-event nasional maupun 
internasional. Berkembangnya dunia Public Relations menjadikan event sebagai salah satu media komunikasi yang digunakan oleh perusahaan. (4) Threats. Panasonic memiliki beberapa competitor, seperti Phillips, Samsung, LG, Sharp. Konsumen memiliki banyak pilihan dalam memilih produk eletronik. Panasonic harus menjadi perusahaan yang dinamis mengikuti perkembangan elektronik yang semakin meningkat, jika Panasonic tidak mengikuti perkembangan maka akan kalah saing.

\section{Strategy}

Langkah kedua yaitu strategy. Dalam langkah ini, perencana merancang ide-ide atau konsep yang menarik agar dapat menarik perhatian publik dan media, sehingga program tersebut mendapatkan publisitas yang kredibel dan berhasil meningkatkan citra Panasonic Beauty.

\section{Tujuan dan Sasaran}

Menurut Nager dan Allen (1984) dalam Public Relations Management by Objectives, goals adalah yang menentukan arah dalam menjalankan program Public Relations. Goals dapat diartikan sebagai tujuan untuk jangka panjang, meliputi reputasi, relasi, dan respon berupa aksi publik. Sedangkan objectives diartikan sebagai sasaran yang berupa cara-cara suatu perusahaan atau organisasi dalam mencapai tujuan (goals).

Dalam merencanakan suatu program Public Relations, perencana harus menetapkan sasaran dan tujuan dari kegiatan tersebut. Sasaran Public Relations dalam program ini terbagi menjadi 3, yaitu:

\section{a. Reputation Management Goals}

Reputations management goals adalah sebuah sasaran yang berkaitan dengan pembentukan identitas dan persepsi mengenai perusahaan. Sasaran Panasonic dalam mencapai reputation management goals adalah meningkatkan reputasi Panasonic Beauty dengan menyelenggarakan program Public Relations yang memiliki konsep yang menarik.

\section{b. Relationship Management Goals}

Relationship management goals adalah sebuah sasaran yang berkaitan dengan bagaimana sebuah perusahaan atau organisasi menjalin hubungan dengan publik. Sasaran Panasonic dalam mencapai relationship management goals adalah meningkatkan hubungan yang baik dengan media dan stakeholders.

a. Task Management Goals

Task management goals adalah sebuah sasaran yang berkaitan dengan strategi dan taktik Public Relations dalam melaksanakan programnya.Sasaran Panasonic dalam mencapai task management goals adalah mampu menarik perhatian publik melalui media sosial dan mendapatkan publisitas melalui undangan media yang sesuai dengan sasaran target audience.

Adapun tujuan dari program Public Relations ini terbagi menjadi 3, yaitu:

1. Awareness objectives

Awareness objectives berkaitan dengan informasi yang ingin disampaikan pubik sehingga mereka dapat mengingat dan tertarik terhadap program Public Relations. 
Untuk mencapai awareness objectives, Panasonic merencanakan konsep yang menarik dan perencanaan yang matang, agar target audience merasa tertarik terhadap program Public Relations Panasonic Beauty. Selain itu, perencana terlebih dahulu mensosialisasikan akan diselenggarakannya special event, melalui media sosial Panasonic Beauty, sehingga dapat meningkatkan kesadaran publik terhadap special event tersebut.

2. Acceptance objectives

Acceptance objectives berkaitan dengan bagaimana publik merespon informasi yang telah diterima. Untuk mencapai acceptance objectives, Panasonic Beauty memberikan edukasi tentang kecantikan terhadap setiap kalangan target audience sehingga berpengaruh terhadap pembentukan reputasi Panasonic Beauty.

3. Action objectives

Action objectives berkaitan dengan terbentuknya opini (verbal action) dan perilaku (physical action) setelah terselenggaranya program Public Relations tersebut. Action objectives dalam penyelenggaraan special event Panasonic Beauty adalah meningkatnya reputasi Panasonic Beauty dan mempererat hubungan antara Panasonic dengan media dan publiknya.

\section{Menentukan strategi respon}

Menurut Ronald Smith (2009, p.82), strategi proaktif adalah strategi yang cocok digunakan dalam merencanakan suatu program Public Relations. Strategi proaktif adalah strategi berupa inisiatif dalam melaksanakan program komunikasi sesuai dengan kondisi dan jadwal yang telah ditentukan, untuk kepentingan perusahaan atau organisasi. Berikut adalah perencanaan strategi Public Relations Panasonic Beauty, antuk mencapai suatu tujuan dan kesuksesan strategi, yaitu:
a. Press Conference
b. Special Events
c. Publications
d. Collateral Materials

\section{Strategi Penyampaian Pesan}

Berkaitan dengan perencanaan program Public Relations, perencana tentunya memiliki pesan (key message) yang ingin disampaikan kepada publik. Key message berupa statement yang memuat tujuan utama suatu program komunikasi. Key message juga dapat digunakan sebagai dasar dalam membuat strategi dan taktik untuk program yang akan dilakukan, sehingga perencana dapat menentukan strategi yang paling efektif agar key message dapat diterima dengan baik oleh publik.

Pesan dari perencana yang ingin disampaikan melalui kegiatan ini adalah "Brave to be yourself to emit beauty in your own way.", yaitu motivasi bagi para perempuan agar dapat lebih percaya diri dengan apa yang mereka miliki melalui caranya tersendiri. 


\section{Tactics}

Tactics adalah penjabaran strategi apa saja yang akan dilakukan untuk sebuah program Public Relations. Sesuai dengan strategi dan key message yang telah disusun, maka taktik dilakukan agar menyempurnakan dan mensukseskan strategi tersebut.

Sesuai dengan strategi dan key message yang telah disusun, maka taktik dilakukan agar menyempurnakan dan mensukseskan strategi tersebut, yaitu:

\section{1) Press Conference}

Untuk melakukan pendekatan, memberikan informasi kepada media mengenai special events Panasonic, serta menjalin hubungan yang baik dengan media, maka perencana akan menyelenggarakan Press Conference pada tanggal 21 September 2017. Perencana tentunya terlebih dahulu membuat undangan untuk para media, agar media tertarik untuk menghadiri press conference. Undangan berupa e-mail dan akan dikirim 1 minggu sebelum pelaksanaan press conference. Setelah undangan dikirim, perencana akan mengkonfirmasi kedatangan media, 2 hari sebelum terselenggaranya press conference. Perencana akan mengundang 40 media yang sudah disegmentasikan sesuai dengan target audience Panasonic Beauty. Press Conference tersebut akan kami laksanakan 2 minggu sebelum special events dimulai, diadakan di gedung Panasonic Gobel Indonesia yang ber-alamat J1. Dewi Sartika No.14 (Cawang II), Jakarta 13630, Indonesia.

2) Special Events

Panasonic Beauty membuat rangkaian special event oleh Panasonic Beauty, berupa roadshow campus-to-campus bernama "Girls Beauty Room by Panasonic Beauty", berlangsung selama 1 bulan di universitas yang berbeda perminggu-nya. Kampuskampus pilihan untuk special event tersebut adalah Universitas Bina Nusantara, Universitas Trisakti, Universitas Paramadina, dan Universitas Atmajaya. Acara ini dilaksanakan dalam waktu 1 bulan pada setiap hari Kamis yaitu tanggal 5, 12, 19, dan 26 Oktober pada pukul $10.00-17.00$.

\section{a. Mobile Salon}

Special events yang terdiri dari mobile salon dan free hairstyling untuk para mahasiswi. Panasonic Beauty akan menghadirkan hairstylist yang akan melakukan demo produk secara langsung kepada mahasiswi. Melalui mobile salon, para mahasiswi dapat merasakan product experience dan free hairstyling oleh hairstylist Panasonic Beauty.

Untuk design mobile salon, akan digunakan container berwarna pink, yang diisi dengan properti-properti seperti sofa, kursi, meja, dan produk-produk Panasonic Beauty sebagai peralatan untuk free hairstyling. Selain itu, akan dipasang juga sebuah screen, sebagai media promosi Panasonic Beauty.

b. Talkshow "Beauty is You"

Selain itu, perencana turut menyelenggarakan talkshow bertema "Beauty is You". "Beauty is You" merupakan acara talkshow yang membahas tentang beragam cara merawat diri, tips-tips seputar kecantikan, make up tutorial dan 
hairstyle untuk mahasiswi, serta motivasi untuk dapat menumbuhkan rasa percaya diri. Talkshow akan berlangsung di setiap auditorium universitas tersebut. Peserta yang telah mendaftar untuk mengikuti talkshow dan hadir, akan mendapatkan free merchandise dari Panasonic Beauty berupa make up pouch. Akan terdapat foodstall di auditorium tempat pelaksanaan talkshow, yang berisi hidangan makanan ringan untuk para mahasiswi.

Untuk menarik minat mahasiswi, maka perencana memilih beauty influencer sebagai pembicaranya. Beauty influencer yang dipilih sebagai pembicara adalah Abel Cantika, seorang beauty blogger dan youtuber, yang juga berstatus sebagai mahasiswi. Pemilihan terhadap beauty influencer tersebut, diharapkan dapat memberi inspirasi kepada mahasiswi sebaya dalam hal kecantikan.

Untuk acara talkshow "Beauty is You", akan berlokasi di aula atau auditorium kampus. Konsep juga masih dengan nuansa pink pastel, seperti untuk properti yang akan diletakkan di stage talkshow. Pada venue talkshow, perencana juga menyediakan foodstall yang berisi makanan-makanan ringan seperti cupcake dan mini cake dengan dekorasi bernuansa pink dan girly. Para peserta talkshow dipersilahkan menyantap kue-kue yang terdapat di foodstall setelah selesai acara talkshow.

c. Photobooth Competition

Untuk meningkatkan publisitas, perencana juga membuat photobooth competition untuk para mahasiswi. Photobooth dirancang sesuai dengan konsep "girly" dan "teenager" agar mahasiswi merasa tertarik untuk berfoto dan mengunduh foto mereka ke Instagram. Para mahasiswi dapat berpartisipasi dengan cara berfoto di photobooth yang telah disediakan, lalu di unduhke Instagram dengan menggunakan hashtag \#BraceYourself dan di mention ke akun Instagram @panasonicbeautyid. Tiga foto yang paling unik akan mendapat hadiah berupa produk-produk Panasonic Beauty yang akan diumumkan 2 minggu setelah acara selesai. Dengan adanya partisipasi mahasiswi untuk berfoto di photobooth dan meng-upload ke Instagram, makadiharapkan publisitas mengenai event akan meningkat.

3) Publications

Melalui sosial media, perencana melakukan publikasi kepada publik, yaitu Facebook dan Twitter Panasonic, serta Instagram Panasonic Beauty. Perencana akan melakukan publikasi 1 minggu sebelum acara berlangsung, yaitu pada tanggal 29 September 2017.

Untuk publikasi diFacebook, perencana akan mem-posting di Facebook Panasonic Indonesia, mulai dari 2 minggu sebelum acara diselenggarakan. Posting Facebook akan dilakukan 1 kali dalam sehari, pukul 10.00. 
Untuk publikasi di Twitter, perencana akan mem-posting di Twitter Panasonic Indonesia, mulai dari 1 minggu sebelum acara diselenggarakan. Posting Twitter akan dilakukan 2 kali dalam sehari, pukul 13.00 dan 19.00.

Untuk publikasi di Instagram, perencana akan mem-posting di Instagram Panasonic Beauty, mulai dari 2 minggu sebelum acara diselenggarakan. Posting Instagram akan dilakukan 1 kali dalam sehari, pukul 19.00. Posting pertama akan berisi "sneak peek" mengenai speaker talkshow "Beauty is You", yaitu Abel Cantika. Setelah mem-posting "sneak peek" mengenai pembicara talkshow, perencana akan mem-posting flyer promosi acara "Girls Beauty Room by Panasonic Beauty" untuk memberi informasi mengenai tanggal dan waktu penyelenggaraan acara di masing- masing kampus. Posting flyer akan dilakukan 3 hari sebelum acara di masing masing kampus pada pukul 19.00. Setelah acara selesai dimasing masing kampus, perencana juga akan memposting 3 foto dokumentasi saat acara berlangsung.

\section{4) Collateral Materials}

a. Printed Media

Perencana akan menggunakan printed media untuk mempromosikan acara. Pada program ini, printed media yang akan digunakan adalah flyer, banner, dan poster.

b. Press Kit

Untuk memberikan informasi seputar Panasonic dan Panasonic Beauty, perencana membuat press kit yang dikemas dengan goodie bag Panasonic Beauty. Isi press kit berupa greeting card, company profile, press release, fact sheet, dan merchandise (flashdisk).

c. Goodie Bag

Panasonic Beauty akan menyediakan goodie bag untuk para peserta talkshow "Beauty is You" sebagai merchandise. Goodie bag Panasonic Beauty akan diisi dengan greeting card, leaflet produk-produk Panasonic Beauty, notebook, dan make up pouch.

Gambar 1. Logo “Girls Beauty Room by Panasonic Beauty"

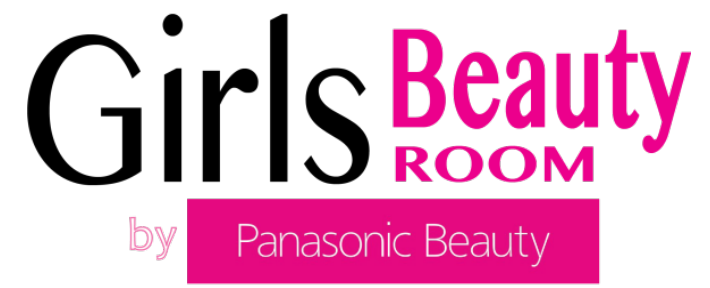

Sumber: Rancangan Pembuat Karya (2017) 


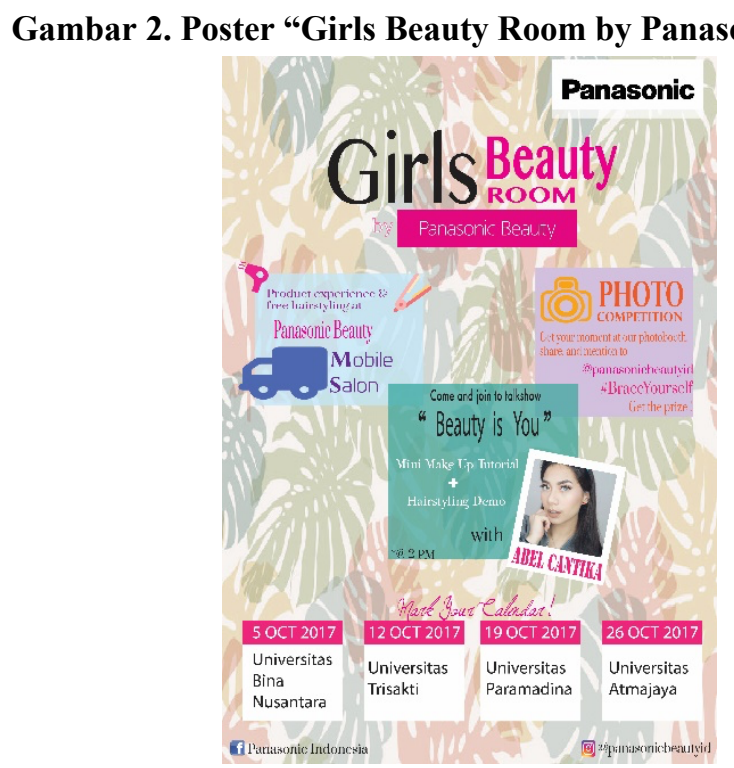

Sumber: Rancangan Pembuat Karya (2017)

\section{Gambar 3. Design Photobooth}

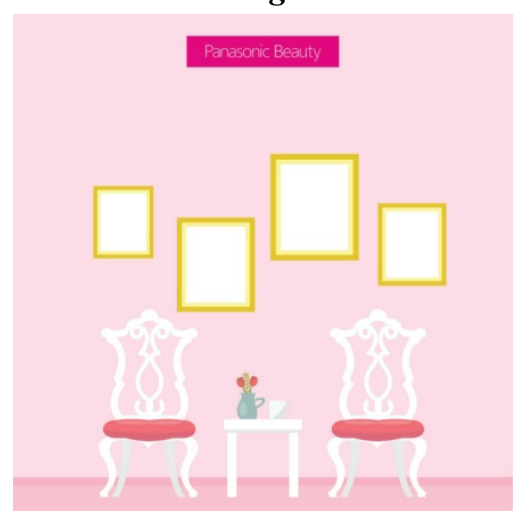

Sumber: Rancangan Pembuat Karya (2017)

\section{Implementasi}

Selanjutnya adalah tahap implementasi dari strategi dan taktik yang telah direncanakan. Pada tahap implementasi program, terdapat dua hal yang perlu diperhatikan oleh perencana, yaitu :

1. Timeline

Adanya perencanaan waktu secara matang akan membuat program Public Relations terselenggara secara tepat waktu dan lebih terorganisir. Oleh karena itu, perencana membuat rancangan timeline sebagai acuan untuk menentukan waktu berjalannya program yang telah direncanakan. Timeline dapat dibuat berupa kalender atau time table dengan keterangan-keterangan kegiatan yang harus dituntaskan secara tepat waktu, mulai dari persiapan hingga tahap evaluasi program selesai.

2. Budget

Dalam menyusun program Public Relations, perencana hendaknya mengetahui pasti anggaran biaya yang dibutuhkan. Menurut Vera Wijayanti dalam bukunya 
Dasar-Dasar Humas, Perencanaan program Public Relations haruslah disesuaikan dengan anggaran yang tersedia.Besar atau kecilnya anggaran sangat mempengaruhi berapa lama program akan berjalan, media apa saja yang bisa digunakan, berapajangkauan sebuah program akan di jalankan, apakah jangkauannya lokal, nasional atau internasional. (Vera, 2010, p.70) Budget disusun secara sistematis dengan berbentuk angka, berisi rincian dan total perkiraan jumlah pengeluaran yang akan terpakai.

\section{Evaluative Research}

Langkah terakhir adalah evaluation research. Evaluasi digunakan untuk mengukur keberhasilan program Public Relationsyang telah dijalankan. Selain itu, adanya evaluasi juga dapat memberitahu perencana mengenai kelebihan dan kekurangan program tersebut sehingga dapat menjadi bahan perbaikan untuk program selanjutnya.

Terdapat beberapa jenis evaluasi yang dapat digunakan oleh perencana sesuai dengan tujuan program yang telah dilaksanakan, yaitu :

\section{1) To evaluate awareness objective}

Berfokus kepada isi pesan, menganalisis berapa banyak orang yang mengetahui dan menerima pesan, seberapa mudah pesan dapat dipahami, dan seberapa besar pesan tersebut dapat diingat oleh publik. Terdapat dua metrics dalam kategori pertama, yaitu :

a) Menghitung berapa banyak media coverage dan media impressions.

b) Menganalisis seberapa besar awareness publik terhadap program.

2) To evaluate acceptance objective

Menganalisis seberapa besar publik dapat menerima program yang telah dilaksanakan. Terdapat empat metrics dalam kategori kedua, yaitu:

a) Menghitung berapa banyak publik yang mencari informasi mengenai program.

b) Menganalisis tanggapan dan perilaku publik setelah mendapat informasi mengenai program.

c) Menghitung berapa banyak respon positif atau ketertarikan publik terhadap informasi program, melalui e-mail, surat, dan telepon.

d) Evaluasi berapa banyak publik yang menerima dan memahami tujuan program.

3) To evaluate action objective

Berfokus kepada seberapa banyak publik yang berpartisipasi, observasi secara langsung, dan mengukur seberapa efektif program dalam meningkatkan hubungan dengan media. Terdapat tiga metrics dalam kategori ketiga, yaitu :

a) Menghitung berapa banyak partisipan, melalui penjualan tiket, jumlah kehadiran, donasi, dan lain-lain.

b) Mengukur seberapa besar kesuksesan program.

c) Menganalisis apakah ada perubahan, baik dalam organisasi maupun lingkungan, setelah pelaksanaan program. 
Kesuksesan special event "Girls Beauty Room by Panasonic Beauty" dapat diukur melalui evaluasi Terdapat beberapa langkah evaluasi yang digunakan, yaitu:

1. Menghitung berapa banyak media yang hadir pada saat pelaksanaan acara dan saat pelaksanaan press conference melalui registration list media. Media yang diundang saat pelaksanaan press conference adalah 40 media. Dapat dikatakan berhasil apabila 25 media hadir dalam acara press conference dan 20 media hadir saat pelaksanaan special event "Girls Beauty Room by Panasonic Beauty".

2. Menghitung berapa banyak partisipan special event. Perhitungan partisipan akan dihitung dengan menggunakan alat checker.

3. Menganalisis antusiasme dari partisipan special event. Antusiasme partisipan dapat diukur melalui berapa banyak yang mengikuti acara mobile salon, diukur oleh SPG mobile salon dengan menggunakan checker. Partisipan talkshow dapat diukur menggunakan registration list peserta. Target partisipan untuk acara talkshow adalah 100 orang dan dapat dikatakan berhasil apabila 75 orang datang menghadiri acara tersebut.

4. Menghitung berapa banyak publik yang memberikan retweet atau ikut mempublikasikan acara (twitter), berapa banyak like, comment dan publik yang turut mempublikasikan acara (facebook, instagram, dan youtube). Dapat dikatakan berhasil apabila publikasi yang telah dilakukan oleh Panasonic Beauty mendapatkan 100 like atau repost.

5. Melakukan media monitoring setiap harinya untuk menganalisis berapa banyak berita mengenai acara tersebut. Media monitoring berlangsung selama 24 hari dimulai dari tanggal 30 Oktober sampai dengan 25 November.

Menghitung berapa persen citra Panasonic Beauty meningkat setelah dilaksanakan acara tersebut melalui jumlah penjualan produk Panasonic Beauty. Pengukuran dapat digunakan melalui survey yang dilakukan oleh tim Corporate Communications dari Panasonic.

\section{SIMPULAN}

Berdasarkan perencanaan strategi Public Relations untuk Panasonic Beauty, maka terdapat beberapa saran oleh perencana yang ditujukan kepada pihak penyelenggara yaitu tim Corporate Communications Panasonic. Adapun, saran yang diberikan adalah meningkatkan kreatifitas dalam membuat tema dan konsep acara untuk target audience yang berbeda, contohnya seperti konsep untuk kalangan anak muda dan konsep untuk kalangan wanita yang sudah dewasa.

Selain itu, Panasonic Beauty hendaknya memperluas cakupan daerah untuk melaksanakan kegiatan special events. Adanya keberagaman tema dan banyaknya wilayah pelaksanaan kegiatan Public Relations Panasonic Beauty, diharapkan dapat mencakup setiap kalangan dan mampu mengangkat publisitas, reputasi serta citra Panasonic Beauty. 


\section{DAFTAR PUSTAKA}

Butterick, K. (2013). Pengantar Public Relations: Teori dan Praktik. Raja Grafindo Persada.

Cutlip, S. M., Center, A. H., \& Broom, G. M. (2006). Effective Public Relations (9th ed.). Pearson Education.

Jefkins, F., \& Yadin, D. (2003). Public Relations (5th ed.). Erlangga.

Laermer, R., \& Prichinello, M. (2009). Full Frontal PR: Getting People Talking about You, Your Business, or Your Product. Bhuana Ilmu Populer.

Ruslan, R. (2001). Manajemen Humas \& Manajemen Komunikasi: Konsepsi dan Aplikasi. Rajawali Press.

Ruslan, R. (2008). Kiat dan Strategi Kampanye Public Relations. Raja Grafindo Persada.

Smith, R. D. (2005). Strategic Planning for Public Relations (2nd ed.). Lawrence Erlbaum Associates. 